\title{
Evaluation of Chinese Homework in Primary School: Connotation, Problems and Strategies
}

\author{
Tianyue Li, Jumei Xiao \\ Huzhou Teachers College, Zhejiang, China
}

\begin{abstract}
As an important part of teaching activities, Chinese homework is an important means for Chinese teachers to achieve teaching objectives. At present, there are some problems in Chinese homework, such as the simple evaluation method, the emphasis on process evaluation, the single evaluation subject, the "marriage" of evaluation task, and the "lag" of feedback of evaluation results. For this reason, we should use the evaluation methods of pattern, stratification, and evaluation, and pay attention to the evaluation strategies of teachers, students, and their network platform.
\end{abstract}

Keywords: Chinese homework, effective evaluation, evaluation subject

\section{The Connotation of Primary School Chinese Homework Evaluation}

\section{An Analysis of the Concept of Chinese Homework in Primary School}

The word "homework" originated from the English word, which originally refers to the paid production of clothing, shoes, and hats at home in the early stage of industrialization. With the gradual prevalence of class teaching, homework was introduced into the teaching field. The early use of homework in school education is German educator Herbart (2002), who advocated the students to use and practice the knowledge in the class, after-class in the book General Education. In order to set aside more time for school study, the work was left at home. Since then, homework has become a continuation of classroom teaching (p. 125). The explanation of "homework" in "education dictionary" refers to the learning activities that students independently carry out in their extracurricular time according to the requirements of teachers. Arranging and checking homework is one of the teaching organization forms. It is generally believed that it is an extension of classroom teaching, which helps to consolidate and improve the knowledge and skills learned by students in class and to cultivate students' independent learning ability and habits (Gu, 1990, p. 212). The explanation in the Concise Encyclopedia of International Education is that "Homework is a learning task assigned by teachers to students and required to be completed outside the classroom" (Comparative Education Research Office of Central Institute of Education Science, 1990, p. 32). Chinese scholar, Shi Liangfang's (1999) view on homework is that "the school homework arranged formally requires to be completed after class” (p. 32). It includes a series of activities, such as reviewing old lessons, preparing new lessons, expanding research and extracurricular self-study projects, and further self-study (Shi, 1999, p. 32). In a word, the definition of time here refers to all the time except the time during the class. As long as the work is completed within this time, it can be called homework. However, in

Tianyue Li, M.A., College of Teacher Education, Huzhou Teachers College.

Jumei Xiao, Ph.D., associate professor, College of Teacher Education, Huzhou Teachers College. 
addition to the time in class, students can finish their homework under the guidance of teachers or in the discussion with their classmates. Therefore, this concept is not accurate enough, more similar to work rather than homework. According to Chen Long'an (1999), homework is a creative learning process that students do at home. It is too narrow, just referring to homework done at home and ignoring other places. To sum up, homework generally refers to "tasks assigned by teachers to students in schools and completed in non school time” (p. 267). That is, "homework has become a continuation of classroom teaching” (Wang, 2010, p. 11).

Chinese is the abbreviation of language and literature, and it can also be the abbreviation of language and characters. It is the essence of human culture. It integrates science and art. It is a very important humanities and social subject. Therefore, it is very important to cultivate students' good Chinese ability. The Chinese Curriculum Standard of Compulsory Education (2011 Edition) mentioned that "the basic feature of Chinese curriculum is the unity of instrumentality and humanity. Chinese curriculum should be committed to the cultivation and development of students' Chinese quality" (Ministry of Education of the People's Republic of China, 2011). Among them, instrumentality refers to that Chinese can be used as a means of communication, while humanity refers to human civilization and culture carried by Chinese. And Chinese homework is to help students consolidate, understand, and use the Chinese knowledge and skills they have learned, cultivating students' independent learning ability, improving their Chinese literacy and humanistic cultivation, and making students form correct outlook on life and values. Homework evaluation is the evaluation of students' homework, mainly from the aspects of students' attitude and quality. It is not only a way for students to consolidate knowledge, use what they have learned to solve problems and improve their academic development, but also a way for teachers to give feedback on teaching (Wang, 2017, p. 230). The common homework evaluation methods are qualitative evaluation method and percentage system evaluation method. However, as a diversified and open subject, Chinese homework often has no standard answer. Only these two methods can not realize the knowledge and experience that students need from homework. And primary school students spend at least one hour in Chinese homework every day. With a series of student decompression policies issued by the Ministry of Education, how can students achieve the best effect in the limited homework time? Therefore, we should pay attention to the effective evaluation of primary school students' Chinese homework.

\section{The Value of Primary School Chinese Homework Evaluation}

The value of homework cannot be reflected without effective homework evaluation. The research shows that the effect is quiet different whether the students can get the teacher's evaluation after doing homework. For example, Paschel and others found that only homework assignments without feedback from teachers on homework can only improve learning to a medium extent, and giving feedback on students' homework, such as rating, scoring, and commenting, has a greater positive impact on students' learning (Yao, 2004, p. 142). Compared with rating and giving scores, writing comments has a greater positive impact on students. Therefore, effective homework evaluation, that is to maximize the efficiency of students' homework, cannot only consolidate students' knowledge and skills, but also cultivate students' correct values. Specifically, the value of primary school Chinese homework evaluation mainly lies in the following three aspects:

It can promote the communication between teachers and students. In a short time, teachers can learn about students' recent learning and inner thoughts through their homework. For a long time, teachers can understand students' learning habits, learning characteristics, and development trends. And teachers can use this point, according to the characteristics of different students, to use personalized evaluation methods for 
students, stimulating students' interest in learning, so that students get a higher level of development. Chinese homework evaluation provides teachers with a bridge to further understand students. How to use this bridge to communicate with students depends on the art of teacher evaluation?

Students can find their mistakes in time. For example, the misunderstanding of new words and new words, the deviation of reading and composition understanding, or the mistakes of their own learning attitude and learning habits can be reflected through homework evaluation. This requires teachers make targeted evaluations of students' homework and seriously grade the students' homework, or write down the mistakes of students directly, or guide students to find out the mistakes and find out the reasons. Let students understand where there are mistakes and why there are mistakes, so as to avoid repeating them.

It can stimulate the development of students. Teachers can write encouraging comments to students with learning difficulties and praise their every progress. When students find that their efforts are found and praised by teachers, they will take their homework more seriously. Teachers can also put forward higher requirements for students who have spare power to learn, encourage students to challenge themselves, play their potential, and achieve self-development. Because of the effective evaluation of homework, it forms a virtuous circle of students' learning and promotes the development of students.

\section{Problems in the Evaluation of Primary School Chinese Homework}

Since the eighties of last century, most of the educational reference books published in our country have adopted the view of Kellov. At present, most of the primary and secondary schools implement the homework advocated by Kellov (Ren, 2010, pp. 7-10). This view regards teachers as the center and is too rigid and serious, which is not conducive to the development of students. With the new curriculum reform and quality education put forward, more and more people begin to pay attention to homework, but people's attention only stays on "quantity" rather than "quality". In other words, people pay more attention to the design of homework, but ignore the research on the effective evaluation of homework. Therefore, most of the domestic teachers still use the traditional evaluation method for primary school Chinese homework evaluation, which has the following problems.

\section{Simple Evaluation Method}

The current evaluation method of primary school Chinese homework is monotonous and uninteresting, which cannot arouse the enthusiasm of students to write homework. For copying homework, teachers will use symbols representing right and wrong to evaluate students' homework, or draw a five pointed star or a smiling face at the bottom of the homework. For reading, writing, and other cumulative homework, most teachers only writes a simple "read" which represents that the homework has been checked, only a few teachers will write comments on students' homework. On the one hand, these general evaluation methods cannot let students know where their mistakes are, and do not understand the standard of teachers' evaluation of homework. On the other hand, students' hard work results only exchange for perfunctory evaluation, which makes students feel unbalanced and negative.

\section{Pay More Attention to Effect than Process Evaluation}

In the process of homework evaluation, teachers pay too much attention to whether students' answers are consistent with the standard answers, and ignore the process of students' homework. In the eyes of teachers, homework is only a tool to help students consolidate what they have learned. What kind of thinking can 
students get the right answer? Why do students do this problem wrong? Even if the student's answer does not match the standard answer, is it correct from another perspective? These problems are rarely studied by teachers. For some open homework, such as reading and writing, teachers only write a score, which cannot well tap students' potential thoughts and abilities.

\section{Single Evaluation Subject}

In the compulsory education Chinese Curriculum Standard (2011 Edition), it is mentioned that teachers and students should give full play to their initiative and creativity in teaching. Students are the main body of Chinese learning and teachers are the organizers and guides of learning activities. Chinese teaching should be carried out in the process of equal dialogue between teachers and students (Ministry of Education of the People's Republic of China, 2011). At present, homework evaluation is generally conducted by teachers, but students, as the main body of learning, cannot participate in homework evaluation, and there is no interaction between teachers and students. The task of homework evaluation is so many that teachers cannot help themselves. And this kind of evaluation method with teachers as the main body will make the evaluation results have great limitations, which will inevitably affect the effect of students' learning.

\section{Feedback of Evaluation Results “Lag”}

For students' homework, most teachers only choose an important part to correct. Some of them even do not. For example, for basic exercises, such as new words and new words, the teacher will basically skip them. For oral reading and recitation, the teacher will select several students to answer in class; for homework, such as diary and composition, the teacher will focus on correcting. Similar to some basic exercises, teachers usually take them in every few days and send them to students after a simple check. This way of evaluating homework will greatly weaken the effectiveness of homework feedback. According to teachers' evaluation attitude to different assignments, students' seriousness in various assignments will be different. In the long run, students will become a "homework machine” without feelings.

\section{"Distribution" of Evaluation Tasks}

The original intention of homework evaluation is to let parents also participate in students' learning, so that family education and school education can help students learn together. But some teachers give the task of correcting homework to their parents completely and ask them to correct and sign. Although it is necessary for parents to participate in the supervision of homework, it is also inappropriate to overemphasize the role of parents in homework evaluation. Sometimes, excessive participation of parents does not play a positive role. On the one hand, parents do not have much time and energy to check homework for students, which becomes a kind of burden for parents. On the other hand, parents do not have professional learning and excessive participation will make homework lose the effect of feedback.

\section{The Strategy of Primary School Chinese Homework Evaluation}

The effective evaluation of Chinese homework is aimed at improving students' Chinese literacy. It is also mentioned in the evaluation proposal of the new curriculum that "the basic purpose of Chinese curriculum evaluation is to promote students' learning and improve teachers' teaching”. Chinese course evaluation should accurately reflect students' learning level and learning situation, and comprehensively implement the Chinese course objectives” (Ministry of Education of the People’s Republic of China, 2011). However, in view of the above problems in primary school Chinese homework, we can adopt the following strategies. 


\section{Using a Variety of Methods to Evaluate}

The combination of multiple evaluation methods can give full play to the best effect of Chinese homework evaluation. Specifically, the following methods can be used:

Graphic evaluation method. Students of different ages have different preferences for different evaluation methods. The students in the lower grade of primary school are more interested in vivid and interesting patterns. Teachers can replace ticks and crosses which are full of indifference with smiling and crying emoticons, which cannot only make students clear and correct their mistakes, but also protect their self-esteem. When the students finish their homework carefully, the teacher can make a second evaluation and encourage the students with the thumbs up or the five pointed star. After the students are encouraged by the teacher, they will naturally improve their homework.

Stratified evaluation method. The answer to the assignment is not the only criterion to evaluate the students' assignment. Teachers can find many encouraging points from students' homework. Layered evaluation method, that is, students can get teachers' affirmation when they reach different levels of standards. For example, students can be praised for their high accuracy in homework, for their neat writing, and for their progress in homework. This kind of evaluation method can make students feel the recognition of teachers, so that their attitude towards homework will become serious.

Comment evaluation method. For primary school students in the middle and senior grades, the common pattern evaluation cannot meet their emotional needs. With the emergence of composition and reading, students' homework needs more guidance and feedback from teachers. According to the learning situation of different students, the evaluation of comments can be more specific and personalized. Teachers can write expectations or affirmative evaluations on students' homework. When finding students' mistakes, they should timely point out and encourage students to continue their efforts. When they find the bright points of students, they should also be sure and praise in time.

Reward evaluation method. Every student is eager to be praised and encouraged by the teacher. The teacher can reward the students who perform well according to the psychological characteristics of the students. Now, many schools are adopting this method. According to the quality of students' homework, students can get some rewards from teachers. For example, books, pens, or according to the completion of students' homework, students with good performance can get the right to reduce homework, the right to change seats, and so on. The reward evaluation has a great incentive effect on the primary school students, especially the lower grade students.

\section{Pay Attention to the Participation of Various Subjects in the Evaluation}

Effective homework evaluation requires teachers, students, and platforms to participate in various aspects.

Students participate in evaluation. As the main body of learning, students should participate in homework evaluation, which mainly includes self-evaluation and mutual evaluation. Self-evaluation means that students find problems in their homework. This method can promote students' self-reflection and find their advantages and disadvantages from reflection, so as to know which place to pay attention to in the next homework, and which is helpful for students' self-improvement. Students' mutual evaluation is the mutual evaluation among students, such as desk mates' review and group mutual evaluation. Students can help each other to find out their own or others' shortcomings in the evaluation process, which can not only promote the common progress of students, but also promote students to increase their understanding and experience of learning. 
Face-to-face evaluation of Teachers. In the opinion on deepening the reform of education and teaching and improving the quality of compulsory education in an all-round way, the Central Committee of the Communist Party of China (CPC) mentioned that teachers should conscientiously correct their homework, strengthen the face-to-face explanation, and give feedback in a timely manner. In particular, we should pay more attention to writing and reading which can reflect students' emotional attitude and values. For students who have completed their homework well or have their own unique ideas, teachers should pay attention to using encouraging language to inspire students and help them improve further. But for some students who cannot finish their homework well or on time, teachers should not rush to reprimand or find parents to solve the problem, but to communicate with students patiently to find the problems in students' study and help them to solve.

Parents and online platforms participate in the evaluation. Parents play more role of supervisor than evaluator in homework evaluation. For creative and open homework, teachers can send students' homework to the group through QQ, Web chat, and other social platforms, let parents participate in voting or send it to a specific teaching platform for everyone to appreciate and evaluate. This kind of evaluation method can not only lighten the burden for teachers, but also has timeliness. Students can see the feedback information in a short time and correct the improper places. Parents can not only participate in the evaluation of their children's homework, understand their children's development, but also see others' evaluation of their children's homework, and help their children grow up from family education.

\section{Conclusion}

Through the effective evaluation of homework, students can not only better understand and consolidate the knowledge learned in class, but also cultivate their self-study ability and good quality. At present, there are many disadvantages in the evaluation of Chinese homework. Only by solving the problems and using various evaluation methods in time, can we really play the role of homework evaluation and realize the all-round development of students.

\section{References}

Chen, L. G. (1999). Creative thinking and teaching (p. 267). Beijing: China Light Industry Press.

Comparative Education Research Office of Central Institute of Education Science. (1990). Concise Encyclopedia of international education: Teaching (Vol. 2, p. 441). Beijing: Education Science Press.

Gu, M. Y. (1990). Dictionary of education (p. 212). Shanghai: Shanghai Education Press.

Herbart, J. F. (2002). General education (p. 125). (Q. L. Li, Trans.). Hangzhou: Zhejiang Education Press.

Ministry of Education of the People's Republic of China. (2011). Chinese curriculum standard of compulsory education. Beijing: Beijing Normal University Press.

Ren, B. G. (2010). Reflection on Kellov's concept of homework. Global Education Outlook, 39(2), 7-10.

Shi, L. F. (199). Teaching theory: Principles, strategies and research of classroom teaching (p. 32). Shanghai: East China Normal University Press.

Wang, X. (2010). Research on the value orientation of primary school Chinese homework (p. 11). Jilin: Northeast Normal University.

Wang, B. L. (2017). Education curriculum and teaching theory (p. 230). Beijing: Higher Education Press.

Yao, L. M. (2004). Effective teaching research (p. 142). Shanghai: East China Normal University. 